\title{
Envelhecimento por Deformação em Juntas Soldadas de Tubos de Aço API5L $\mathrm{X} 65 \mathrm{Q}$ sem Costura
}

Rodolfo Lisboa Batalha ${ }^{1}$, Leonardo Barbosa Godefroid ${ }^{1}$, Geraldo Lúcio de Faria ${ }^{1}$, Rodrigo Rangel Porcaro ${ }^{1}$, Luiz Cláudio Cândido ${ }^{1}$, Vicente Braz Trindade ${ }^{1}$

1 Rede Temática em Engenharia de Materiais, Departamento de Engenharia Metalúrgica e de Materiais, Universidade Federal de Ouro Preto - UFOP, Ouro Preto, MG, Brasil.

Recebido: 14 Jul., 2015

Aceito: 27 Ago., 2015.

E-mail: rodolfo.batalha@yahoo.com.br (RLB)
Resumo: Neste trabalho, investigaram-se efeitos do fenômeno de envelhecimento por deformação em juntas obtidas por soldagem a arco elétrico com proteção gasosa (GMAW), de tubos sem costura de aço API5L X65Q. Corpos de prova (CPs) obtidos a partir das juntas soldadas foram submetidos à uma deformação plástica a frio de $3 \%$ e posteriormente envelhecidas por $1 \mathrm{~h}$ a $250^{\circ} \mathrm{C}$, de forma a se induzir envelhecimento estático. Buscando avaliar o envelhecimento dinâmico, os CPs foram deformados até $3 \%$ e o carregamento foi mantido durante $1 \mathrm{~h}$ a $250^{\circ} \mathrm{C}$. Os CPs envelhecidos foram submetidos a ensaios de tração e amostras representativas foram analisadas ao microscópio óptico e microscópio eletrônico de varredura. Observou-se que o fenômeno modificou a fração volumétrica de constituintes secundários no metal de solda e na ZTA, com aumento na proporção de agregados ferrita-carbonetos. Com relação às propriedades mecânicas, constatou-se que o fenômeno reduziu a razão elástica das juntas soldadas devido a um aumento no limite de resistência, além de aumentar o alongamento total, não prejudicando, portanto, as propriedades mecânicas em tração das juntas soldadas. Ao se comparar o envelhecimento estático com o envelhecimento dinâmico, observou-se que o aumento na capacidade de deformação plástica das juntas soldadas foi maior após envelhecimento estático por deformação.

Palavras-chave: Tubos sem costura; Aços API5L; Juntas soldadas; Envelhecimento por deformação.

\section{Strain Ageing in Welded Joints of API5L X65Q Seamless Pipes}

\begin{abstract}
In this work was investigated the influence of the strain ageing on joints obtained by gas-metal arc welding (GMAW) of API L L X50 seamless pipes. Specimens were machined from the welded joints, plastically strained to $3 \%$ and aged at $250^{\circ} \mathrm{C}$ for $1 \mathrm{~h}$ posteriorly, in order to characterize effects of static strain ageing. For the dynamic strain ageing characterization, the specimens were simultaneously strained and aged. Then, the aged specimens were submitted to tensile tests and representative samples were analyzed at a light optical microscope and a scanning electron microscope (SEM). From the results, it was observed that the strain ageing phenomenon changed the volumetric fraction of secondary constituents in the weld metal and in the heat-affected zone, increasing the proportion of ferrite-carbide aggregates. Regarding the mechanical properties, it was noticed that the phenomenon led to higher tensile mechanical properties such as ultimate tensile strength and total elongation and lower elastic ratio, and, therefore, not impaired the mechanical properties under tensile of the welded joints. Comparing the static strain ageing with dynamic strain ageing it was observed that the effect on the plastic straining ability of welds was higher after static strain ageing.
\end{abstract}

Key-words: Seamless pipes; API5L steels; Welded joints; Strain ageing.

\section{Introdução}

Durante o enrolamento de dutos submarinos para posterior lançamento ao mar pode ocorrer deformação plástica e eventual envelhecimento por deformação [1,2]. Segundo a literatura, o fenômeno de envelhecimento por deformação causa modificações irreversíveis nas propriedades mecânicas de aços microligados e pode, portanto, prejudicar o desempenho em serviço dos dutos [1-8].

Muitos trabalhos foram realizados para investigar as condições nas quais o envelhecimento por deformação ocorre em aços de alta resistência e baixa liga, bem 
como seus efeitos nas propriedades mecânicas desses aços [1-7,9]. Entretanto, poucos trabalhos consideraram a ocorrência do fenômeno em juntas soldadas.

Os efeitos do envelhecimento por deformação estão relacionados a interações discordâncias-átomos de soluto e as alterações percebidas nas propriedades mecânicas são reflexos de uma redistribuição desses átomos, alojando-se em linhas de discordâncias de forma a diminuir a energia do sistema $[1,4,5,8]$. O fenômeno se evidencia como um aumento na resistência mecânica, que pode ocorrer após ou durante a deformação plástica. Se ocorrer após a deformação, denomina-se envelhecimento estático por deformação e se ocorrer durante denomina-se envelhecimento dinâmico por deformação [8].

Tratando-se de juntas soldadas, sabe-se que, comparativamente ao metal base, há maior densidade de discordâncias em regiões de solda, resultado das transformações de fases durante a operação de soldagem [10]. Dessa forma, haverá uma maior quantidade de discordâncias a serem bloqueadas por átomos intersticiais em regiões de soldas durante o envelhecimento por deformação, com a possibilidade de discordâncias permanecerem livres para se movimentarem. Portanto, espera-se que os efeitos do envelhecimento por deformação em soldas sejam distintos daqueles observados no metal base [10,11].

Neste artigo, apresentam-se os resultados da investigação de efeitos do fenômeno de envelhecimento por deformação sobre a microestrutura e propriedades mecânicas de juntas soldadas ao arco elétrico com proteção gasosa (ou GMAW, do inglês gas-metal arc welding) em tubos sem costura de aço API5L X65Q.

\section{Materiais e Métodos}

\subsection{Materiais e procedimento de soldagem}

Foram utilizados tubos sem costura de aço API5L X65Q (temperado e revenido) [12] provenientes de uma mesma corrida, com dimensões $273,0 \mathrm{~mm}$ de diâmetro externo e $21,44 \mathrm{~mm}$ de espessura de parede.

A soldagem GMAW foi realizada na posição plana com chanfro em $V$ e com arame-eletrodo AWS A5.18 ER70S-6 [13], com 1,2mm de diâmetro. A abertura de raiz do chanfro foi de 1,6mm e foram depositadas cinco camadas de solda. Os parâmetros de soldagem empregados foram: corrente de soldagem de $200 \mathrm{~A}$ em polaridade inversa (eletrodo ligado ao polo positivo), com tensão de $29 \mathrm{~V}$ e velocidade de soldagem de $4,0 \mathrm{~mm} / \mathrm{s}$. $O$ aporte térmico resultante, considerando eficiência térmica de $80 \%$, foi de $1,16 \mathrm{~kJ} / \mathrm{mm}$. Foi utilizada para proteção da poça de fusão uma mistura de gases de argônio $+15 \% \mathrm{CO}_{2}$. Os parâmetros de soldagem foram selecionados em acordo com normas aplicáveis [14].

\subsection{Procedimento experimental}

De forma a se determinar a composição química do metal de solda foi realizada análise química aplicando-se a técnica de espectroscopia de emissão óptica.

Para simular a ocorrência de envelhecimento estático por deformação, corpos de prova de tração retangulares e longitudinais, com a solda na seção útil dos $\mathrm{CPs}$, foram pré-deformados a frio a $3 \%$ a uma taxa de deformação de $\cong 10^{-4} \mathrm{~s}^{-1}$ e posteriormente envelhecidos a $250^{\circ} \mathrm{C}$ por $1 \mathrm{~h}$. De forma a induzir envelhecimento dinâmico, os corpos de prova foram mantidos sob uma deformação plástica de $3 \%$ a $250^{\circ} \mathrm{C}$ por $1 \mathrm{~h}$ [15]. Na Figura 1 apresentam-se os corpos de prova utilizados para simulação do envelhecimento e na Figura 2 observam-se os equipamentos utilizados e o posicionamento do CP durante envelhecimento dinâmico. CPs obtidos do metal base também foram envelhecidos de forma a se comparar efeitos do fenômeno no metal base e nas juntas soldadas.

Após envelhecimento por deformação dos corpos de prova, realizou-se caracterização microestrutural utilizando-se microscopia óptica (MO) e microscopia eletrônica de varredura (MEV). A metalografia quantitativa foi realizada utilizando-se a técnica de contagem de pontos, de forma a se obter a fração volumétrica de fases e constituintes presentes nas regiões da solda. Para a caracterização mecânica, os corpos de prova foram envelhecidos, descarregados e ensaiados em tração. A preparação metalográfica e os ensaios mecânicos foram conduzidos em acordo com as normas aplicáveis [12,15-19]. As análises foram realizadas também no metal base de modo a se comparar com as juntas soldadas. 


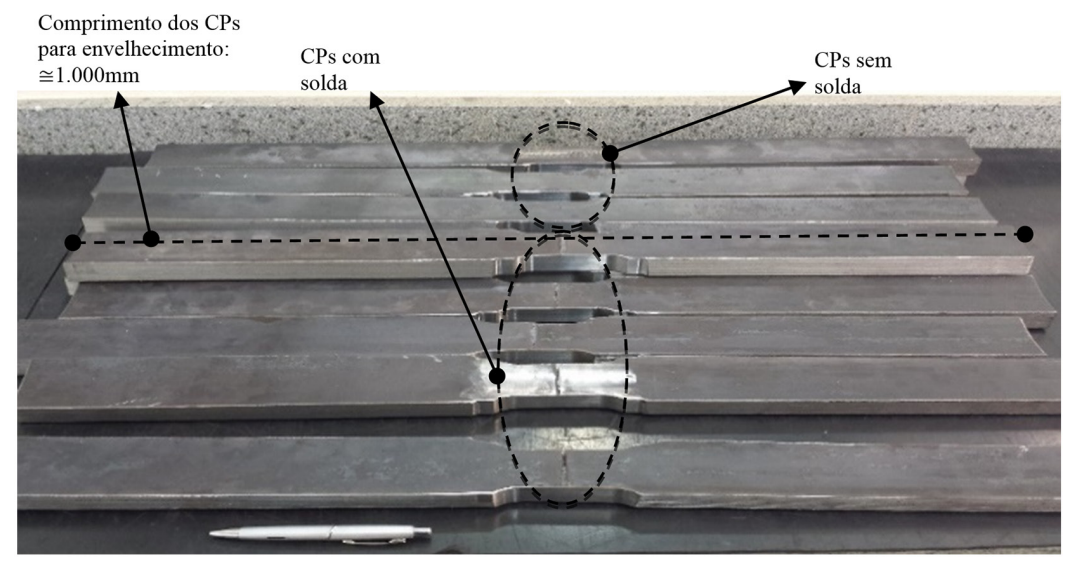

Figura 1. Corpos de prova de tração para simulação do fenômeno de envelhecimento por deformação.

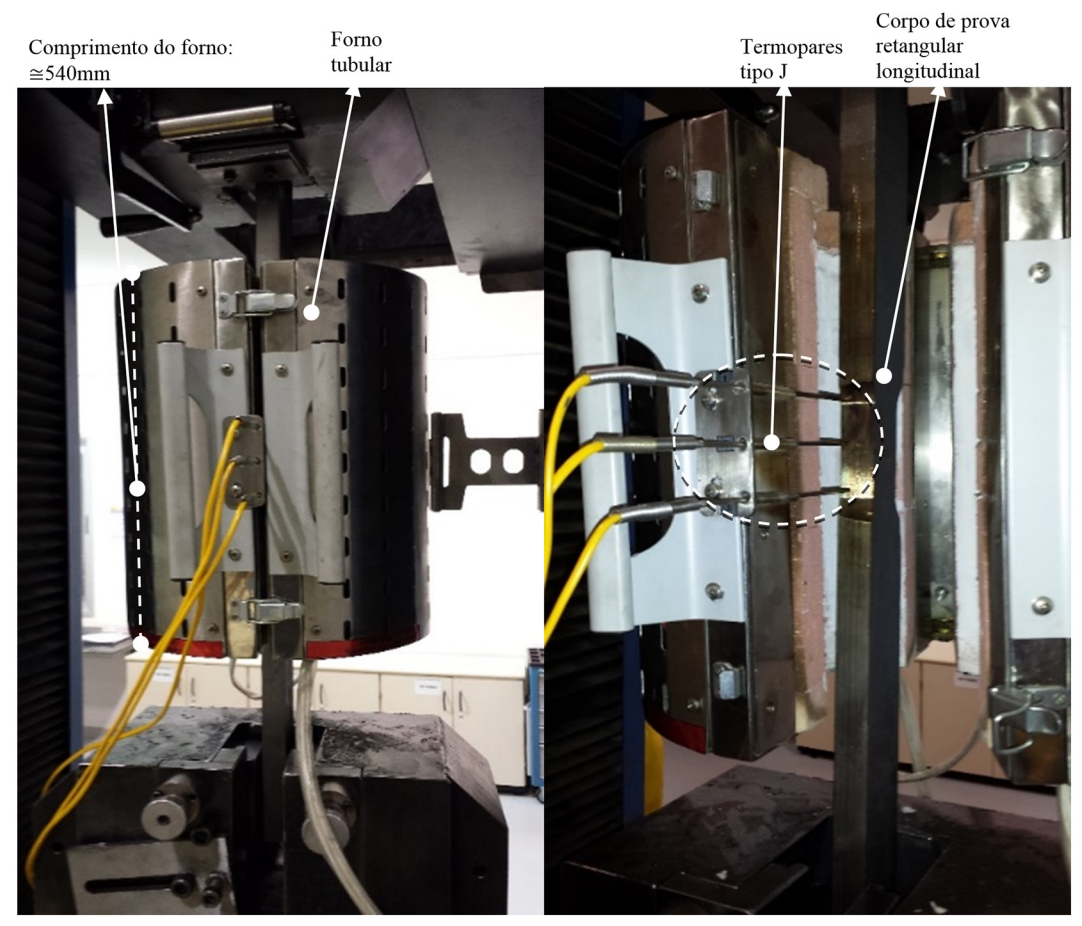

Figura 2. Arranjo para simulação de envelhecimento dinâmico por deformação.

\section{Resultados e Discussão}

\subsection{Análise química}

Na Tabela 1, apresenta-se a composição química e o carbono equivalente do metal de solda. Na Tabela 2, tem-se a composição química nominal do metal base API5L X65Q, segundo norma [12,19].

Analisando os resultados da Tabela 1, pode-se afirmar que a composição química e o carbono equivalente do metal de solda, $\mathrm{CE}_{\| \mathrm{IW}}=0,31$, atenderam o exigido por norma para o aço API5L grau X65Q [12,14,19]. Observa-se também a presença de elementos adicionados para desoxidação da poça de fusão, como $\mathrm{Mn}$, Si e Al. A formação de óxidos desses elementos influencia na microestrutura final do metal de solda, atuando como sítios para nucleação de ferrita intragranular e de ferrita acicular [20-23]. Já os elementos microligantes, como Nb, Ti e V, são responsáveis pela formação de carbonetos na microestrutura do metal de solda [21-23]. Dessa forma, assim como no metal base e na ZTA, deve-se considerar a participação desses carbonetos nos mecanismos responsáveis pelo fenômeno de envelhecimento por deformação das juntas soldadas [4-10]. 
Tabela 1. Composição química do metal de solda (\% em peso).

\begin{tabular}{cccccccccccccccccc}
\hline $\mathbf{C}$ & $\mathbf{S i}$ & $\mathbf{M n}$ & $\mathbf{P}$ & $\mathbf{S}$ & $\mathbf{C r}$ & $\mathbf{M o}$ & $\mathbf{N i}$ & $\mathbf{A l}$ & $\mathbf{C o}$ & $\mathbf{C u}$ & $\mathbf{N b}$ & $\mathbf{T i}$ & $\mathbf{B}$ & $\mathbf{V}$ & $\mathbf{F e}$ & $\mathbf{C E}_{\text {IIw }}$ & $\mathbf{C E}_{\mathbf{P C M}}$ \\
0,08 & 0,86 & 1,29 & 0,015 & 0,011 & 0,015 & 0,027 & 0,049 & 0,001 & 0,002 & 0,073 & 0,004 & 0,001 & 0,001 & 0,002 & Balanço & 0,31 & 0,18 \\
\hline
\end{tabular}

$\mathrm{CE}_{I I W}$ - carbono equivalente, baseado na equação do Instituto Internacional de Soldagem [12]. $\mathrm{CE}_{\mathrm{PCM}}-\mathrm{Carbono}$ equivalente, baseado na equação de Ito-Bessyo [12].

Tabela 2. Composição química nominal do aço API5L X65Q (\% em peso) [12,19].

\begin{tabular}{ccccccccccc}
\hline $\mathbf{C}$ & $\mathbf{S i}$ & $\mathbf{M n}$ & $\mathbf{P}$ & $\mathbf{S}$ & $\mathbf{V}$ & $\mathbf{N b}$ & $\mathbf{T i}$ & $\mathbf{F e}$ & $\mathbf{C E}_{\text {IIw }}$ & $\mathbf{C E}_{\mathrm{PCM}}$ \\
0,16 & 0,45 & 1,65 & 0,020 & 0,010 & 0,09 & 0,05 & 0,06 & Balanço & 0,42 & 0,22 \\
\hline
\end{tabular}

$\mathrm{CE}_{\mathrm{IIW}}$ - carbono equivalente, baseado na equação do Instituto Internacional de Soldagem [12]. $\mathrm{CE}_{\mathrm{PCM}}$ - carbono equivalente, baseado na equação de Ito-Bessyo [12].

\subsection{Caracterização microestrutural}

Na Figura 3, apresenta-se a microestrutura do metal base após ataque químico com reativo Nital 5\%. Os microconstituintes observados foram ferrita e bainita, resultante da composição química e dos tratamentos térmicos de têmpera seguido de revenimento nos tubos.

Na Figura 4, apresenta-se a microestrutura do metal de solda na condição como soldado (sem envelhecimento) obtida no MEV. Pela aplicação da técnica de metalografia quantitativa a fração volumétrica das fases e constituintes no metal de solda foram $39 \%$ de ferrita acicular (FA), 38\% de ferrita primária (FP), $15 \%$ de ferrita de Widmansttäten (FW) e $8 \%$ de agregados ferrita-carbonetos (FC).

De acordo com a literatura $[20,22,23]$ o constituinte martensita-austenita retida (M-A) pode ser identificado por microscopia óptica utilizando-se o reativo Le Pera (uma mistura de uma solução de $1 \mathrm{~g}$ de metabissulfito de sódio em $100 \mathrm{ml}$ de água destilada com outra solução de $4 \mathrm{~g}$ de ácido pícrico em $100 \mathrm{ml}$ de etanol, na proporção de 1:1). Entretanto, o ataque revelou além da presença de $M-A$, agregados ferrita-carbonetos (FC). Na Figura 5 observa-se as distintas morfologias do constituinte M-A do FC que, segundo a literatura, são identificados após confirmação da microdureza do M-A (aproximadamente 500HV) [22,23].

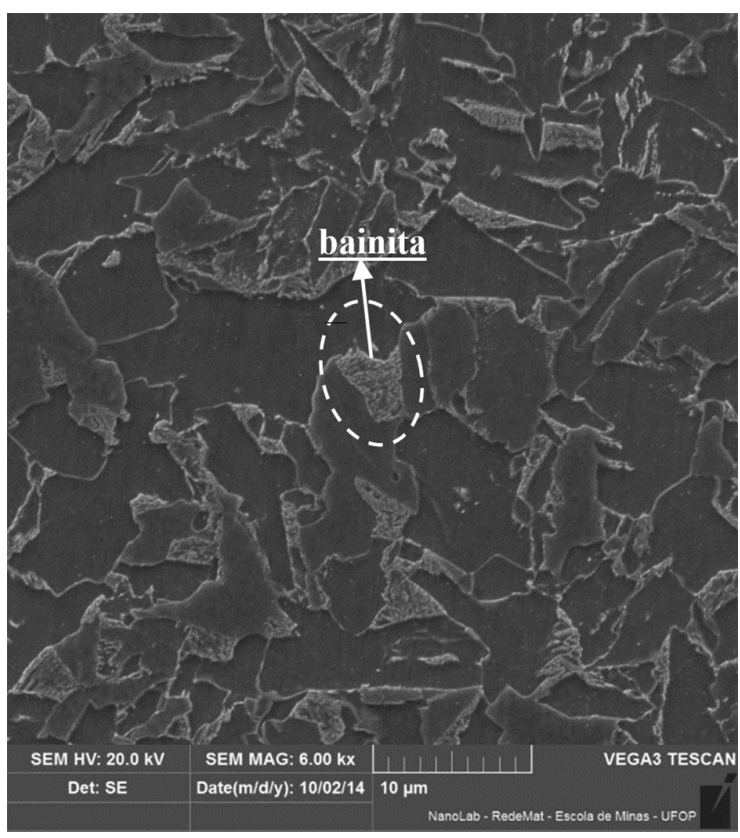

Figura 3. Microestrutura do aço API5L X65Q (metal base) observada no MEV. 


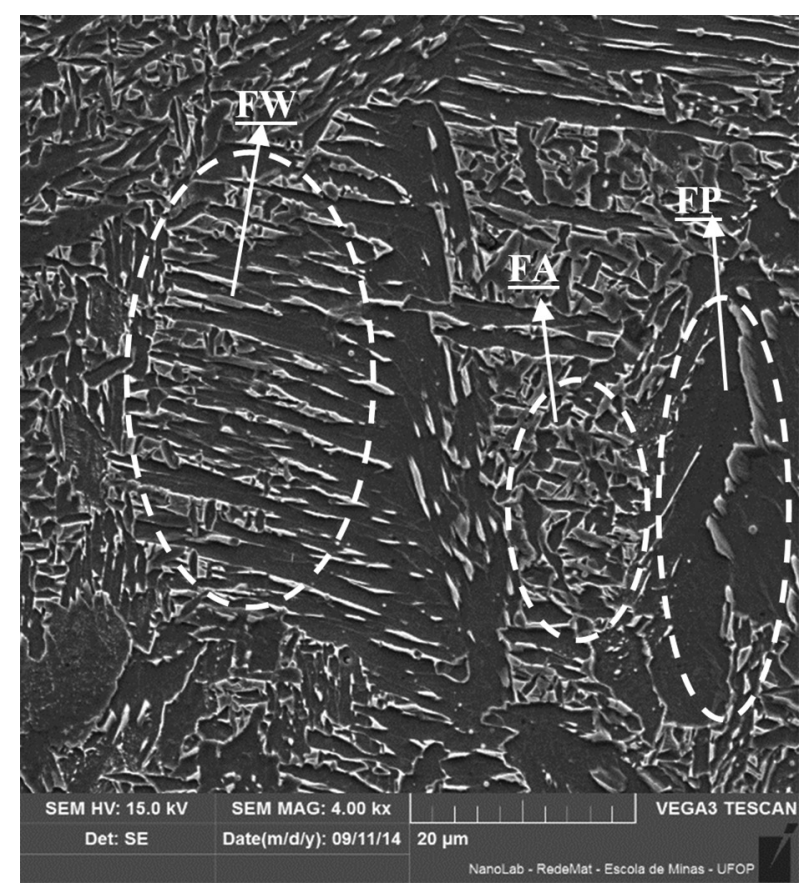

Figura 4. Microestrutura do metal de solda no MEV. FA - ferrita acicular; FP - ferrita primária; FW - ferrita de Widmansttäten. Nital $5 \%$.

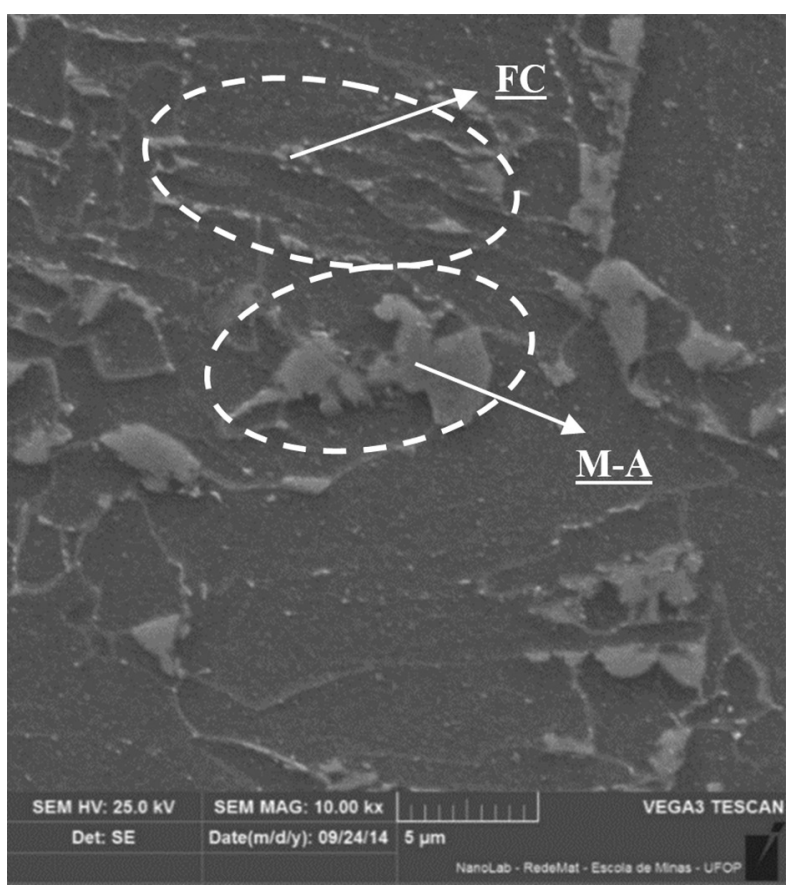

Figura 5. Micrografia da ZTA (sem envelhecimento) obtida no MEV mostrando a identificação dos constituintes M-A e FC após ataque com reativo Le Pera.

A Tabela 3 apresenta as frações volumétricas obtidas por metalografia quantitativa em micrografias ópticas das regiões das juntas soldadas, nas condições estudadas. Observou-se que ocorreu uma modificação após envelhecimento por deformação na fração volumétrica de constituintes secundários - agregados ferrita-carbonetos e/ou M-A. 
Tabela 3. Fração volumétrica de constituintes secundários agregados ferrita-carbonetos e/ou M-A nas condições estudadas.

\begin{tabular}{cccccc}
\hline $\begin{array}{c}\text { Constituintes } \\
\text { secundários no } \\
\text { metal de solda } \\
\text { sem envelheci- } \\
\text { mento }\end{array}$ & $\begin{array}{c}\text { Constituintes } \\
\text { secundários no } \\
\text { metal de solda } \\
\text { após envelhe- } \\
\text { cimento estático } \\
\text { por deformação }\end{array}$ & $\begin{array}{c}\text { Constituintes } \\
\text { secundários no } \\
\text { metal de solda } \\
\text { após envelheci- } \\
\text { mento dinâmico } \\
\text { por deformação }\end{array}$ & $\begin{array}{c}\text { Constituintes } \\
\text { secundários } \\
\text { na ZTA sem } \\
\text { envelhe- } \\
\text { cimento }\end{array}$ & $\begin{array}{c}\text { Constituintes } \\
\text { secundários } \\
\text { na ZTA após } \\
\text { envelhecimento } \\
\text { estático por } \\
\text { deformação }\end{array}$ & $\begin{array}{c}\text { Constituintes } \\
\text { secundários } \\
\text { na ZTA após } \\
\text { envelhecimento } \\
\text { dinâmico por } \\
\text { deformação }\end{array}$ \\
\hline & $9 \%$ & $8 \%$ & $6,5 \%$ & $12 \%$ & $23 \%$ \\
\hline
\end{tabular}

Apesar de não se ter conduzido análises por microscopia eletrônica de transmissão, acredita-se que durante o envelhecimento das juntas soldadas, átomos de carbono se difundiram em direção às discordâncias de forma a formarem as atmosferas de Cottrell, encontrando elementos de liga substitucionais que também se alocaram ao redor das discordâncias, o que pode explicar a maior fração volumétrica de constituintes secundários. Considerando os mecanismos responsáveis pelo fenômeno de envelhecimento por deformação em aços microligados [1-9,24] e supondo elevadas densidades de discordâncias nas regiões da solda [10,11], acredita-se que o fenômeno causou um aumento de agregados ferrita-carbonetos em detrimento do constituinte $M-A$, com um aumento mais pronunciado na ZTA. Este mecanismo foi proposto para explicar o fenômeno de envelhecimento por deformação em aços microligados [1-9,24].

\subsection{Propriedades mecânicas}

A Figura 6 apresenta as curvas obtidas durante envelhecimento dinâmico por deformação de um corpo de prova de metal base e o outro obtido a partir das juntas soldadas, de forma a compará-los durante o envelhecimento dinâmico. É possível observar o escoamento descontínuo na curva do metal base, característico do efeito denominado Portevin-Le Chatelier, mostrando que o aço estudado é susceptível a envelhecimento dinâmico por deformação nas condições estudadas.

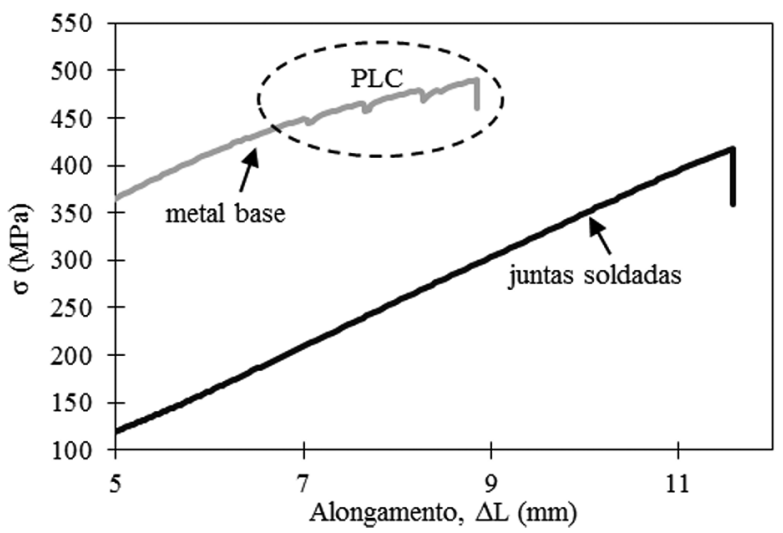

Figura 6. Curvas obtidas durante envelhecimento dinâmico por deformação de um corpo de prova de metal base e outro obtido a partir das juntas soldadas. PLC - efeito Portevin-Le Chatelier.

Nas juntas soldadas não se observou o escoamento descontínuo. Acredita-se que esse comportamento se deve à maiores densidades de discordâncias nas regiões das soldas, devido às transformações de fases durante a soldagem por fusão a arco elétrico com proteção gasosa, predominantemente por mecanismo displacivo [10,11,20-24]. Dessa forma, mesmo que ocorra difusão de átomos intersticiais e formação de atmosferas de Cottrell no metal de solda, poderá haver discordâncias livres para se movimentarem durante a deformação plástica, o que pode ter viabilizado o escoamento plástico contínuo dos corpos de prova [10,11]. 
A Tabela 4 apresenta os resultados obtidos nos ensaios de tração, após o envelhecimento dinâmico dos CPs. Para o metal base, as propriedades mecânicas apresentadas foram obtidas no ensaio para caracterização do aço no estado de entrega. Analisando o efeito do fenômeno de envelhecimento por deformação nas propriedades mecânicas em tração das juntas soldadas, observa-se que houve aumento na tensão limite de resistência, levando a uma diminuição significativa na razão elástica. Além disso, o envelhecimento por deformação levou a um aumento no alongamento percentual total das juntas soldadas. Assim, pode-se afirmar que o envelhecimento por deformação aumentou a capacidade de deformação plástica em tração das juntas soldadas.

$\mathrm{Na}$ Figura 7, tem-se o micro mecanismo de fratura de um corpo de prova de tração das juntas soldadas. A fratura ocorreu no metal base. Assim, o mecanismo de fratura observado para as juntas soldadas sem envelhecimento e para as soldadas submetidas a envelhecimento por deformação é predominantemente nucleação, crescimento e coalescimento de microcavidades (dimples), características de comportamento dúctil.

Tabela 4. Propriedades mecânicas do metal base no estado de entrega e das iuntas soldadas nas condicões estudadas.

\begin{tabular}{lcccc}
\multicolumn{1}{c}{$\begin{array}{c}\text { Propriedades } \\
\text { mecânicas }\end{array}$} & $\begin{array}{c}\text { Metal base (estado } \\
\text { de entrega) }\end{array}$ & $\begin{array}{c}\text { Comolições } \\
\text { envelhecimento) }\end{array}$ & $\begin{array}{c}\text { Como soldado (após } \\
\text { envelhecimento } \\
\text { estático) }\end{array}$ & $\begin{array}{c}\text { Como soldado (após } \\
\text { envelhecimento } \\
\text { dinâmico) }\end{array}$ \\
$\mathrm{LE}(\mathrm{MPa})$ & 496 & 517 & 507 & 516 \\
$\mathrm{LR}(\mathrm{MPa})$ & 617 & 538 & 590 & 580 \\
$\mathrm{AL}(\%)$ & 50 & 10 & 26 & 15 \\
$\mathrm{RE}(\mathrm{MPa} / \mathrm{MPa})$ & 0,80 & 0,96 & 0,86 & 0,89 \\
\hline
\end{tabular}

LE - Limite de escoamento, LR - limite de resistência, AL - alongamento percentual total e RE - razão elástica.

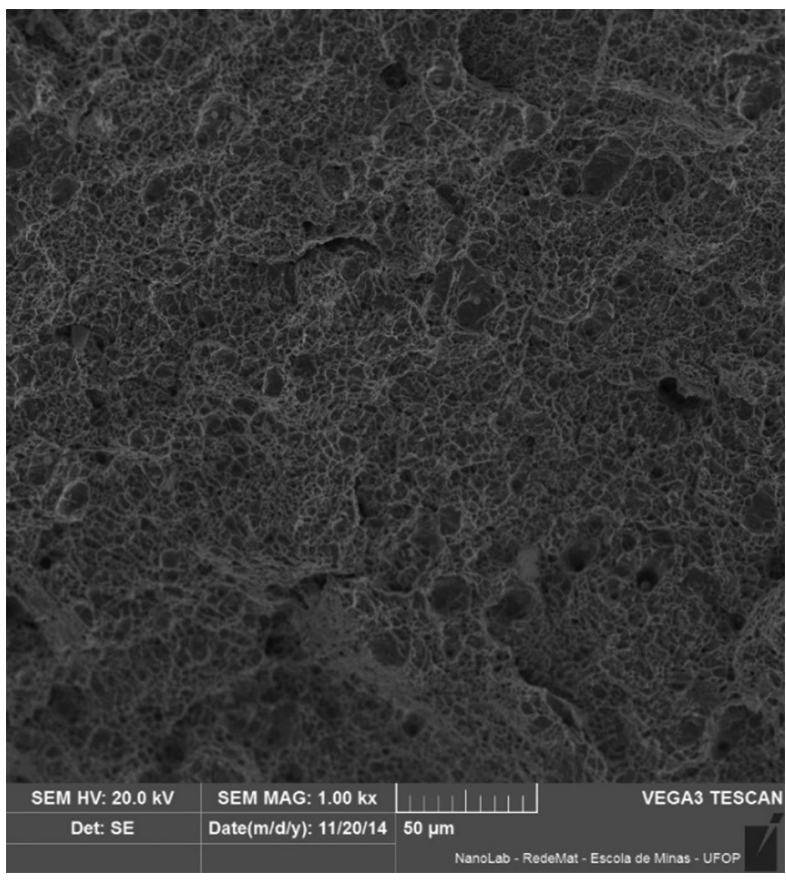

Figura 7. Microfractografia obtida no MEV de corpo de prova de juntas soldadas ensaiado em tração. Mesmo comportamento foi observado para as juntas soldadas submetidas a envelhecimento por deformação. 


\section{Conclusões}

O aço API5L X65Q mostrou-se susceptível ao envelhecimento por deformação nas condições estudadas. As juntas soldadas também apresentaram susceptibilidade ao envelhecimento por deformação, mas os efeitos do fenômeno foram distintos daqueles do metal base, induzindo um aumento na capacidade de deformação plástica das juntas soldadas.

O envelhecimento por deformação modificou as frações volumétricas de constituintes secundários no metal de solda e na ZTA. Acredita-se que ocorreu um aumento na proporção de agregados ferrita-carbonetos, resultado das composições químicas do metal de solda e do aço estudado e dos mecanismos responsáveis pelo envelhecimento, levando a modificações nas propriedades mecânicas das juntas soldadas.

Ao comparar os efeitos do envelhecimento estático por deformação com os efeitos do envelhecimento dinâmico, observou-se que o primeiro foi responsável por um maior aumento no limite de resistência e no alongamento percentual total das juntas soldadas do que o segundo.

Conclui-se ainda que o fenômeno de envelhecimento por deformação não prejudicou as propriedades mecânicas em tração das juntas soldadas, devido à interação entre os mecanismos responsáveis pelo fenômeno e às microestruturas resultantes no metal de solda e na ZTA.

\section{Agradecimentos}

Os autores deste trabalho desejam agradecer à REDEMAT - Rede Temática em Engenharia de Materiais, à CAPES - Coordenação de Aperfeiçoamento de Pessoal de Nível Superior e à Companhia Vallourec \& Sumitomo Tubos do Brasil, pelo apoio na elaboração do trabalho.

\section{Referências}

[1] Bôas ACCV. Comportamento mecânico e de corrosão do aço X70 sob carregamento cíclico simulando o bobinamento de tubos [dissertação de mestrado]. Belo Horizonte: Universidade Federal De Minas Gerais; 2012.

[2] Meissner DA, Erdelen-Peppler DM. Impact of reel-laying on mechanical pipeline properties investigated by full- and small-scale reeling simulations. In: The International Society of Offshore and Polar Engineers. Proceedings of the Nineteenth International Society Offshore and Polar Engineering Conference; 2009 July 21-26; Osaka, Japan. Osaka: ISOPE; 2009.

[3] Leslie WC. The physical metallurgy of steels. 1. ed. Auckland: McGraw-Hill Book Company; 1982.

[4] Gündüz S. Dynamic strain aging effects in niobium microalloyed steel. Ironmaking and Steelmaking. 2002;29(5):341-346.

[5] Staiger MP, Brownrigg A, Hodgson PD, Davies CHJ. Multistage strain aging of low-carbon steels. Materials Science and Engineering A. 2004;364(1-2):35-47.

[6] Mohan R, Marschall C. Cracking Instabilities in a low-carbon steel susceptible to dynamic strain aging. Acta Materialia. 1998;46(6):1933-1948. http://dx.doi.org/10.1016/S13596454(97)00423-0.

[7] Samek L, Moor E, Penning J, Speer JG, Cooman BC. Static strain aging of microstructural constituents in transformation-inducedplasticity steel. Metallurgical and Materials Transactions A. 2008;39A(11):2542-2554.

[8] Abbaschian R, Abbaschian L, Reed-Hill RE. Physical metallurgy principles. 4. ed. Stanford: Cengage Learning; 2009.

[9] Cottrell AH, Bilby BA. Dislocation theory of yielding and strain ageing of iron. Proceedings of the Physical Society. Section A. 1948;62(1):49.

[10] Mandziej ST. The effect of nitrogen and strain aging of c-Mn steel welds. Scripta Metallurgica et Materialia. 1992;27(7):793798. http://dx.doi.org/10.1016/0956-716X(92)90394-T.
[11] Banerjee A, Dhal SK. Effect of strain ageing in welded and non-welded low carbon steel [doctor thesis]. Rourkela: National Institute of Technology; 2010.

[12] American Petroleum Institute. API 5L-09: Specification for line pipe. Washington: API; 2008.

[13] American Welding Society. AWS A5.18/18M-05: Specification for carbon steel electrodes and rods for gas shileding arc welding. Miami: AWS; 2005.

[14] American Petroleum Institute. API 1104-10: Welding of pipeline and related facilities. Washington: API; 2010.

[15] American Society for Testing and Materials. ASTM E21-09: Standard test method for elevated temperature tension tests of metallic materials. West Conshohocken: ASTM; 2009.

[16] American Society for Testing and Materials. ASTM E3-11: Standard Guide for preparation of metallographic specimens. West Conshohocken: ASTM; 2011.

[17] American Society for Testing and Materials. ASTM E 562-02: Standard test method for determining volume fraction by systematic manual point count. West Conshohocken: ASTM; 2002.

[18]. American Society for Testing and Materials. ASTM A370-09A: Standard test methods and definitions for mechanical testing of steels products. West Conshohocken: ASTM; 2009.

[19] Det Norske Veritas As. DNV-OS-F101: Offshore standard. Submarine pipeline systems. Hovik: DNV; 2013.

[20] Trindade VB Fo, Guimarães AS, Payão JDC Fo. Normalizing Heat treatment effect on low alloy steel weld metals. In: Proceedings of the II Brazilian Manufacturing Congress; 2003 May 18-21; Uberlândia, Brasil. Uberlândia: ABCM; 2003.

[21] Kou S. Welding metallurgy. 2. ed. Hoboken: Wiley Interscience; 2003. 
[22] Hrivnak I, Matsuda F, Ikeuchi K. Investigation of M-A constituent in high strength steel welds. Transactions of JWRI. 1992;2122:149-171.

[23] Hrivnak I, Matsuda F, Li Z, Ikeuchi K, Okada H. Investigation of metallography and behaviour of $\mathrm{M}-\mathrm{A}$ constituent in weld
HAZ of HSLA steels. Transactions of Japan Welding Institute. 1992;21-22:101-110.

[24] Vitovec FH. Strain aging and formability of HSLA line pipe steels. Journal of Materials for Energy Systems. 1980;2(1):83-88. http:// dx.doi.org/10.1007/BF02833400. 